\title{
Supersizing e-learning: What a CoI survey reveals about teaching presence in a large online class
}

\author{
Lynette Nagel ${ }^{\mathrm{a}, *}$, Theuns G. Kotzé ${ }^{\mathrm{b}}$ \\ a Department for Education Innovation, University of Pretoria, South Africa \\ b Department of Marketing \&' Communication Management, University of Pretoria, South Africa
}

\section{A R T I C L E I N F O}

Available online $\mathrm{xxxx}$

Keywords:

Large class

e-learning

Higher education

Post-graduate

Peer review

Community of Inquiry

Teaching presence

\begin{abstract}
A B S T R A C T
The answer to massification in higher education lies not in paper-behind-glass style e-learning. Such courses lack the necessary interaction to ensure success. There are perceived upper limits to where e-learning can be up scaled to accommodate large classes. The Community of Inquiry framework provides a convenient instrument to assess the quality of teaching in an online course. All three of teaching, social and cognitive presences should be at an acceptable level to maintain successful learning. We report on a super-sized class for post-graduate students who received instruction over a distance employing a learning management system and email for communication. By using available functionalities in innovative ways, the one full-time lecturer ensured student engagement. Participating in double-blind electronic peer review brought a deeper dimension of learning to the class and augmented the teaching, cognitive and social presences in the class.
\end{abstract} (c) 2009 Published by Elsevier Inc.

\section{Introduction}

Due to massification and economic constraints in higher education, class sizes are increasing. Faculty sacrifice feedback and formative evaluation, causing students to lose their connectedness with peers and faculty (Stephen, O'Connell, \& Hall, 2008), and resulting in higher non-completion rates. With the advent of blended learning, higher education institutions are seeking innovative solutions for overworked faculty to cope with increasing class sizes, without sacrificing support and retention (Hughes, 2007). The web provides convenient access to and interaction in courses. Learning management systems (LMSs) are becoming more flexible in automating some of the tedious aspects of teaching and freeing up capacity for better quality contact time (Feldstein \& Masson, 2006). More students are demanding convenience in their study timetables, as more have employment priorities. Traditional contact teaching institutions are responding to student needs and providing some fully online courses. As a result, there is a boom in online courses worldwide. Unfortunately, not all online courses provide high quality learning experiences, as many consist of little more than books behind glass with little or no interaction.

* Corresponding author. Postal address: Department for Education Innovation, University of Pretoria, Hillcrest, 0002, Pretoria, South Africa. Tel.: +27 124202131 (office), + 27824542248 (mobile).

E-mail addresses: lynette.nagel@up.ac.za (L. Nagel), theuns.kotze@up.ac.za (T.G. Kotzé).
There are many studies on teaching large contact classes. Their success often depends on employing tutors or teaching assistants to augment interaction (Heppner, 2007; Messineo, Gaither, Bott, \& Ritchley, 2007; Stephen et al., 2008). Traditional paper-based distance learning institutions process large numbers of students while adhering to their own quality standards (Holmberg, 1989). The throughput rate in traditional distance education is, however, disappointing.

The requirements for successful online teaching have been refined and validated over the past decade (Anderson, 2004; Garrison, Anderson, \& Archer, 2000). Research shows that the ideal size of online classes are between 25 and 30 students (Arbaugh \& BenbunanFinch, 2005), with studies that argue for the ideal of about 16 students. Unfortunately, we do not live in an ideal world and our real classes differ substantially from the norm regarding student to teacher ratios. Implementing e-learning in a supersized class creates novel challenges, particularly regarding interaction and maintaining presence. "We need to research on how to scale up the size of ALN courses and still teach them effectively. We need more case studies of effective 'large' ALN classes” (Arbaugh \& Benbunan-Finch, 2005, p. 137).

\section{Background}

\subsection{Community of Inquiry}

Successful e-learning starts with proper instructional design. "Course design and presentation mechanisms - together with excellence in online dialogue facilitation separate the excellent online course from the mediocre or weak one" (Collison, Elbaum, Haavind, \& Tinker, 2000, p. 1). Students drop out of classes when they cannot use 
the computer functionalities, cannot find the content, feel lonely or neglected (Rovai \& Wighting, 2005). "Findings indicated that clarity of design, interaction with instructors, and active discussion among course participants significantly influenced students' satisfaction and perceived learning" (Swan, 2001, p. 306).

The Community of Inquiry framework is a valid and dependable instrument to measure the quality of online teaching, focusing on the three important components that contribute to good courses (Arbaugh et al., 2008; Shea, Pickett, \& Pelz, 2003; Swan et al., 2008). Faculty can use this instrument to design and evaluate effective learning environments. The CoI measures three presences: Social, Teaching and Cognitive. These presences overlap and are related to each other. They all contribute towards the formation of a learning community.

\subsection{Social presence}

Developing a learning community benefits both students and faculty, as it can lead towards better retention of students. In turn, course throughput rates increase (Santovec, 2004). There are different views on what route to follow to enable such a community to establish itself. Gilly Salmon (2003) describes five stages in the development of an online community, and the role that the facilitator should take. Initial stages include the provision of access, motivation and online socialization. The level of engagement later deepens with the advent of content-related exchanges and culminates in cognitively challenging activities in the later stages of knowledge construction and development (Salmon, 2003). Salmon implies that socialization is an initial online activity. Although Conrad also showed that an online community develops in stages, her study showed that students initially engaged with cognitive activities. Only after a considerable period did spontaneous social interaction occur in the cohort, more or less concurrent with the development of the community (Conrad, 2005).

Instructor immediacy causes a feeling of closeness or belonging and also improves both affect and cognitive learning (Baker, 2004). According to the CoI, social presence indicates whether the participants see themselves as part of a community to which they feel they belong, in this case the classroom or cohort. Students should feel free to express themselves openly in the environment without fear of rejection and convey their own personalities and feelings (affects) (Arbaugh et al., 2008).

\subsection{Cognitive presence}

Cognitive presence is evident when students purposefully construct knowledge in a collaborative way that is typical of a constructivist learning environment (Garrison, Anderson, \& Archer, 2001). Such learning is deep, retained for longer, and develops students' critical thinking skills through a shared understanding.

\subsection{Teaching presence}

Before the course starts, the foundation for teaching presence is laid in course design and organization. Direct instruction and facilitation by the instructor while the course is active also contributes to this presence (Shea et al., 2003; Swan et al., 2008). Design should focus on instructional activities "that deeply engage the mind of the learner" while "the skill of a good teacher is in knowing the best thing to do to advance a given learner to the next stage of understanding a specific kind of learning task" (Woodill, 2004).

Collison et al. (2000) describe different roles online facilitators can play, advocating the "guide on the side" style of facilitation for developing a learning community. The voices that a facilitator should employ when communicating online include: Generative Guide, Conceptual Facilitator, Reflective Guide, Personal Muse and Mediator or Role Play (Collison et al., 2000, p. 103). In essence, these voices bring to the online classroom teaching, social and cognitive presences, called by another name.

Blignaut and Trollip (2003) developed a taxonomy of facilitator postings, dividing them into posts with or without academic content. Non-content-bearing messages could be administrative, affective or "other". Content-related messages could be corrective, informative (providing individual feedback) or Socratic (redirecting the student's argument). Although administrators and students expect to encounter all these types of posts in their classrooms, not all teachers are equally adept at using these voices or presences. Blignaut and Trollip (2005) report that institutions expect instructors to post messages consisting of about a third each affective and informative messages, a quarter Socratic and a sixth corrective messages. In reality, messages consist of nearly half affective, less than a third informative and very small numbers of Socratic and corrective messages. Considering that the latter two types of messages correspond to some extent to the cognitive presence in a classroom, the Blignaut study creates the impression that this is the most demanding category of teaching to satisfy online, and the social presence, as defined by Salmon, and Blignaut and Trollip, the easiest.

\subsection{Class size}

Research shows that the ideal size of online classes is between 25 and 30 students (Arbaugh \& Benbunan-Finch, 2005). Despite perceptions that a class of 16 achieves the highest level of interaction, Orellana (2006) uncovered no relationship between the sizes of classes and actual interaction levels. On the other hand, Tomei (2006) calculated that the ideal online class size was 12 students, based on the $14 \%$ more time online teaching demands to maintain sufficient teacher-student interaction. Hewitt and Brett (2007) found that the total number of words students write in a large class of 19 students, was no more than that written in a much smaller class. Clearly, our large class differed substantially from the ideal portrayed in the literature. In our institution, we faced seemingly insurmountable obstacles in the form of enormous student to teacher ratios that deteriorated annually. The situation called for creative interpretation of theory and innovative use of available resources. The lecturer used the available functionalities in the LMS and email in creative ways to address the challenges in the super-sized class.

\subsection{Peer review}

Asynchronous discussions consisting of initial posts followed by two peer critiques, can enhance student participation in courses. Students learn more effectively due to enhanced involvement with course content, ultimately leading to more satisfaction with the course (Bhagyavati, Kurkovsky, \& Whitehead, 2005; Gehringer, 2001). One of the strategies that can improve the quality of education, particularly in Web-based classes, is electronic peer review. When students assess their co-students' work, the process becomes reflexive: they learn by teaching and by assessing (Topping, 1998). Peer assessment is interactive and dynamic as students assess, critique and make value judgments on the quality and standard of other learners' work, and provide feedback to the authors (Juwah, 2003; Topping, 1998). In online higher education, faculty use asynchronous discussions and other web-based programs in innovative ways to enable peer review. Students benefit when they spend more time on learning tasks by thinking, comparing, contrasting, and communicating. Students also learn by example. Where learning in a community of practice is sometimes incidental, it now becomes more cognitively demanding as review activities can cause the assessor to consolidate, reinforce, and deepen understanding (Boud, Cohen, \& Sampson, 1999; Boud \& Tyree, 1995; Topping, 1998). Students receive 
feedback sooner and in greater quantity from their peers than the tutor alone could have provided (Topping, 1998).

\section{The context of the study}

Because the upper size limit for a successful class depends on contextual factors (Arbaugh \& Benbunan-Finch, 2005), we use those points to describe our class. The subject of this study is a half-year research methodology course for Masters' and Doctoral students in the Faculty of Economics and Management Sciences at the University of Pretoria. Before this course, supervisors had to teach individual students the basics of research methodology; an ineffective application of time and resources. The popularity of this structured foundation course is increasing, as more departments in the Faculty subscribe to it as a prerequisite to formal registration for postgraduate studies. As a result, student numbers are increasing.

The course deliverable was a research proposal, approved by the supervisor and cleared by the ethical committee. Due to the size of the cohort, the lecturer could not evaluate and provide extensive feedback on such numbers of documents. Therefore, we introduced a peer-review process in 2009. Development of research proposals took place in three stages, namely: 1st draft, 2nd draft and Exam project. There was an opportunity to use peer-review for either or both draft documents. Students first submitted documents to Turnitin, an anti-plagiarism programme, received the reports and had the opportunity to improve their drafts. Students used an evaluation rubric to guide the review, whereas supervisors graded the final project for exam purposes.

The level of skills that students bring to the class influences the context. In such a large class, students' skills varied tremendously. Challenges included variable academic standards, students who commit unintended plagiarism, who have poor ESL writing skills and different levels of computer and information literacy. The large cohort of off-campus students taking the class work full-time; some have limited web access especially from home, further complicating the choice of course delivery mode.

The pedagogical model of the lecturer determines much of the context. Having taught this course face-to-face on a smaller scale, the lecturer was well acquainted with the challenges, limitations and expectations of the students. He therefore followed a behaviorist teaching model in order to bring all students up to the same level in report writing skills. Towards this end, he provided scaffolding consisting of detailed supportive instructional material and copious e-mailed feedback. Due to the highly individualized nature of research proposals, the content of the research proposal was handled in a constructivist fashion, where students chose their own topics and scoped these according to the subject. The lecturer did not evaluate content-related aspects; that was the domain of the supervisors.

Software support was evident. The lecturer used a blended mode of course presentation. At a single initial informative contact session where they also received instruction in using the electronic environment, students received a course CD ROM with study material. The lecturer innovatively used specific tools in the LMS, particularly Assignments, Grading Forms, Announcements, Grading forms, online Quizzes, Turnitin anti-plagiarism software, and electronic peer review.

The Group Manager enabled students from the same department to self-enroll into their own discussion groups and communicate with each other. The lecturer developed an electronic document template to identify and rectify the most common writing mistakes students commit. He also used a custom-built computer program to manage, track and distribute documents for peer review, a process that previously required four days per round when performed manually. He communicated with students mostly via e-mail and textmessaging (SMS), as for many students, their only web access was work-place based and firewall restricted. Students received notifica- tion by email when activities in the LMS were due. These combined ICTs dramatically reduced the lecturer's time on corrections and document management, and improved the quality of assignments. Supervisors received better projects and saved the time otherwise spent on correcting scripts.

The Institutional support was limited to training and consultation in e-learning. It did not include any support in the form of teaching assistants or tutors. The biggest challenge therefore was to provide students with sufficient feedback and interaction. The lecturer literally cloned himself by building up a virtual archive of email responses that he dispatched as feedback when needed. Before each new intake, he revised the online course materials by circumnavigating the previous year's most salient issues.

Class size strongly influences context. In 2008, 122 students enrolled of whom 86 (70\%) completed the course. In 2009, 186 students commenced their studies and 162 (87\%) submitted exam projects, officially completing the course. This represents an increased success rate over the previous year, despite a larger cohort. The difference was in the use of peer review in the 2009 course, as we will discuss in detail.

A summary of the peer review process follows.

- Authors submit draft documents via Assignment tool

- Lecturer removes identifiable information, allocates serial number

- Lecturer distributes each document to 2 reviewers

- Reviewers evaluate document using rubric and Track Changes and Comments in MS Word

- Reviewers submit evaluated documents via Assignment tool

- Lecturer returns evaluated documents to authors

- Authors peruse comments

- Authors evaluate comprehensiveness and value of reviews using the attached evaluating form and submit completed form via Assignment tool

- Lecturer returns evaluating forms to reviewers.

\section{Methodology}

The research employed mixed methodologies; two surveys provided qualitative and quantitative data:

\section{- Course feedback relating to the use of the Document checker and the Peer review process \\ - Community of Inquiry survey.}

The survey questions were presented in the LMS Assessments tool in the following format: Multiple choice questions with five options corresponding to a 5 point Likert scale; true/false options to suitable statements and open-ended paragraph-type questions. Students could access the surveys in the weeks following the July deadline for submission of their exam projects. Two students completed the surveys via email. We calculated basic descriptive statistics for the multiple choice items and present the average value of student responses to these questions.

We gathered qualitative data from the open-ended questions in the course feedback questionnaire and analyzed those with the help of ATLAS.ti. We crystallized the results from the two quantitative instruments with the qualitative findings.

Of the present group, 64 students (40\%) responded to the CoI survey and 76 completed the general course feedback.

Fig. 1 shows the age distribution of the students who completed the electronic feedback. It is noteworthy that the class consists predominantly of students younger than thirty-five. Repeating this survey in the future will indicate if the demographics of the cohort changes. 


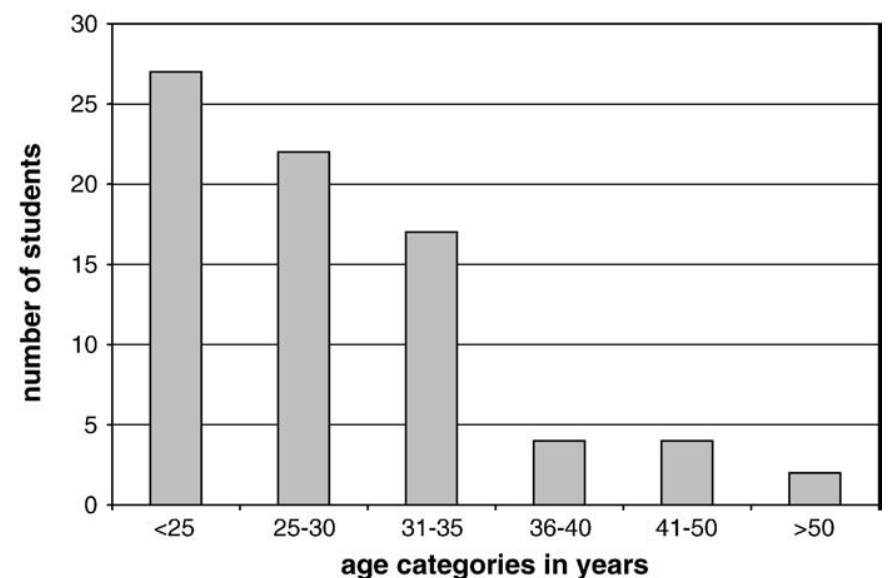

Fig. 1. Distribution of respondents' ages.

\section{Results and discussion}

\subsection{Online resources}

The purpose of the research was to observe whether the available teaching strategies compensated for the large size of the class and the limited personal exposure students had to their lecturer. A number of strategies supported students in mastering high quality academic writing. The online classroom contained numerous systematic and easy-to-follow resources on using the University library and journal databases. To further help students understand academic writing, they could peruse the Turnitin similarity reports. These indicated instances of unacceptable copying from online resources, deficient paraphrasing and incorrect citations. Without any personal intervention from the lecturer, students could master the skills of using academic information resources, while they banished the plagiarism monster.

\subsection{Corrective feedback}

Producing an original, well-formatted academic document in faultless English is a challenge. Students require extensive formative feedback and subsequent practice to master such high-level writing skills. One lecturer was not able to engage with nearly 200 students at the required level, straining the second prerequisite of Swan, Shea, Fredericksen, Pickett, \& Pelz (2000) for good online learning, namely sufficient "interaction with course instructors". The lecturer therefore developed a document checker template that extended the spelling and grammar correction functions of a word processor into highlighting the 64 most common writing mistakes. While use of the programme will help a student to compile a nearly faultless document, the reviewers/markers could verify that documents adhered to the required format and standards, creating more capacity to evaluate the content.

Fig. 2 shows that 16 (21\%) students did not use the document checker at all. The open-ended replies shed light on the reasons. Computer literacy is a limitation, as some students simply could not figure out how to use the programme. Some only use a computer at work, and found that the programme does not function on a network computer. A few reckoned that their writing skills were adequate, and using the computer's default spelling and grammar checking tools, would suffice for them. For 51 (67\%) students, the document checker was useful for both compiling their own and reviewing their peers' documents.

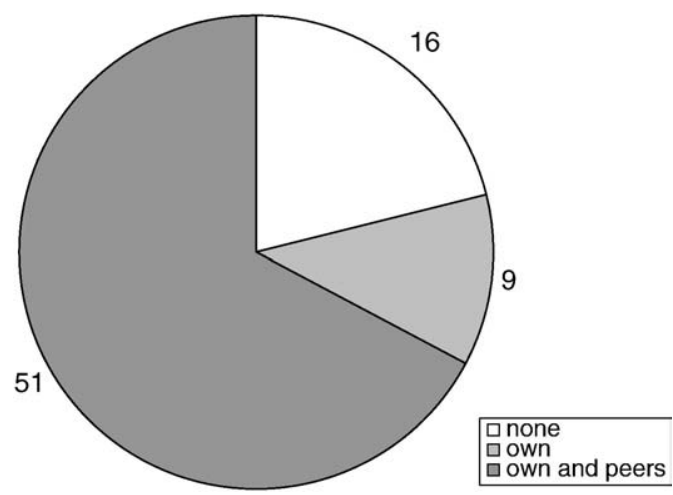

Fig. 2. Percentage of students who used the Doc Checker for their own and peer documents.

\subsection{Peer review}

Student feedback on the peer review process was overwhelmingly positive. In reply to the statement: I am able to produce a better document in future due to the peer review process, $95 \%$ of students replied affirmatively, whereas $96 \%$ of students would furthermore recommend using this process in future courses. By their own choice, a few students engaged in two rounds of peer review for their draft documents. They were very positive about the experience.

\section{“...Students should take part in both reviews"}

Students found both sides of the review process beneficial. They gained much from doing the peer review as well as from receiving their peers' comments. They were likewise enormously positive about the comprehensiveness of the reviews they received, although their two reviewers did not necessarily go to equal trouble to generate a comprehensive review:

"Extremely superficial to Extremely comprehensive (detailed)"

The same dichotomy existed regarding the helpfulness (value) of the review:

“ Not helpful at all to extremely helpful”

In order to uncover the course issues that needed improvement, we asked students: Which aspects of the peer review process did you find least valuable? We coded their responses into three themes that each of the following quotations represents:

"Some students did not do a thorough review. Only one student reviewed my paper"“'The way reviewers tended to concentrate on editorial work. I needed more insights than this"."Evaluating the reviewers".

The first statement represents the very high expectations students have for quality feedback. The second represents a theme that points towards expectations of a higher cognitive level in the review. The third typical statement is not surprising, as students earned no grades for the quality of reviews. Requiring students to evaluate their reviewers enabled the lecturer to monitor the quality of the numerous reviews. There was no incentive in this evaluation for the students; hence, some perceived it as without value. Students' rating to the statement, "Reviewing my peers' proposals was worthwhile", is shown in Fig. 3.

Fig. 3 shows that practically all students conducted at least one worthwhile review. 


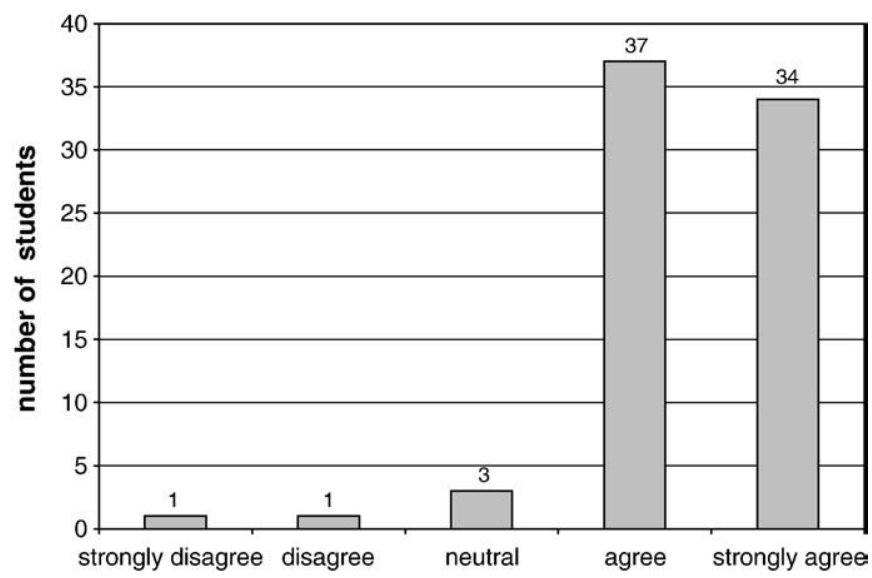

Fig. 3. Survey results of how much students valued reviewing other students' papers.

\subsection{Valuable aspects}

Fig. 4 shows that students valued the feedback from their peers. We coded the responses to the question: Which aspects of the peer review process did you find most valuable? into two themes. The first theme was non-content related, focusing on the technical aspects of producing the document:

"Some highlighted technical things that I had missed"

Peers corrected their language and writing: "grammar, spell checking" "Reference format."

Such corrections have previously been tedious for the lecturer; hence, the document checker automatically executed most of them. Student perceptions to these corrections point towards a teaching presence in the class, albeit automated.

The second theme indicates cognitive value gained from doing the reviews. Most students commented that they "Learnt from what peers did"; "I could compare the quality of my proposal to those I reviewed."

The process also afforded an audience check, as several students were sure that their document portrayed their ideas accurately, only to find that their peers understood it differently:

"A different point of view from another student gave me an indication on how the article would be perceived"

Closely comparing themselves to their peers suggests belonging to a group and indicates a measure of Social presence.

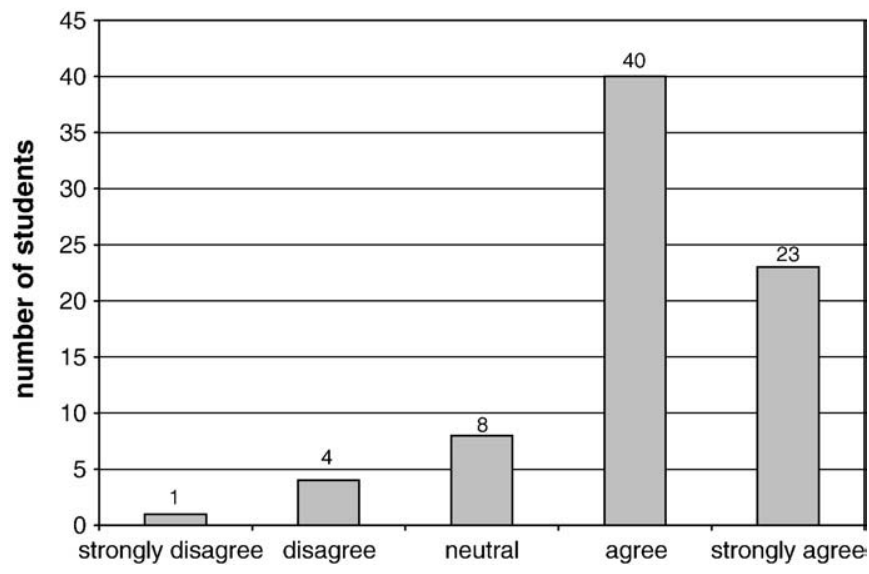

Fig. 4. Survey results of how valuable students found the comments from their peers.
The third theme indicated that feedback was valuable due to addressing subject specific content that was relevant to their research.

"I was fortunate to be reviewed by a person with Tax knowledge.

The feedback often generated new ideas and insights, leading to deeper understanding of their proposed research topic.

"some raised provocative questions"

Students commented on the value of peers' feedback:

"Constructive feedback" "Positive comments, exploratory comments..."

This third grouping of themes indicates a high level of cognitive presence in some of the peer feedback.

Among the replies to all the questions, students expressed sentiments characterized by affective perception that indicated a connectedness with the reviewers through their project. Such replies indicate a social presence resulting from the cognitive engagement.

"Additionally, the idea of 2 peer reviewers is excellent as it means 3 brains/academics are at work on 1 project."

\subsection{Interpretation of the content analysis}

Students expressed a real need for general course related feedback. Having that need satisfied would indicate that there was sufficient teaching presence in the course. The non-content-related, technical feedback from peers indicated such teaching presence. Students also articulated the expectation to encounter contextualised and applied content-related feedback pertaining to their own subject topic. Students' encounters with insightful ideas and challenging suggestions would suggest a high cognitive presence in the class. Valuing the opinions and perspectives of knowledgeable peers suggests more than cognitive presence. Such highly valued cognitive feedback elicited affective reactions and feelings of connectedness also contributing to social presence.

\subsection{Outcomes of the CoI framework}

From Fig. 5, the high score allocated to teaching, suggests that it had the strongest presence in this course.

The construct Design \& Organization scored the highest value of all (Table 1) and contributed to the strength of the teaching presence. This is testimony to the importance of good design, organization and

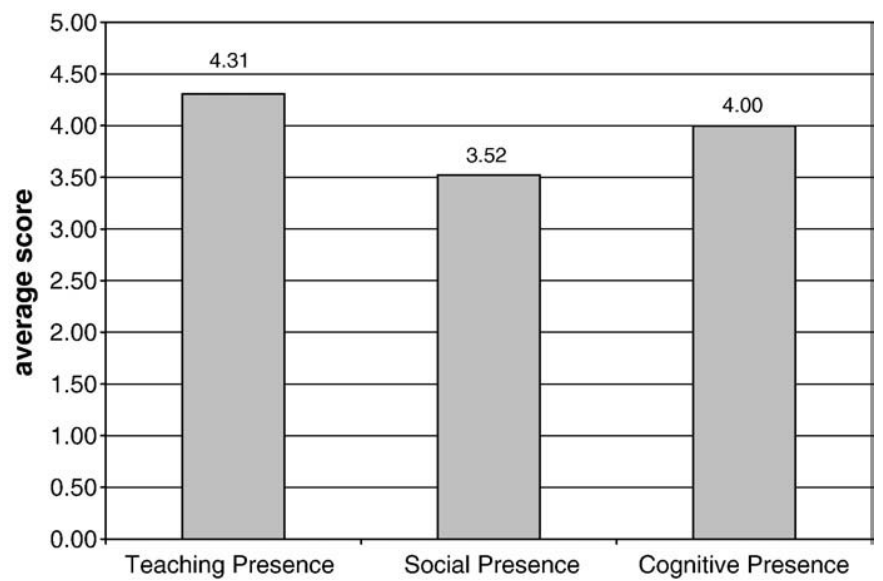

Fig. 5. Average scores of Teaching, Social and Cognitive presences as measured with the Col survey. 
Table 1

CoI construct average values.

\begin{tabular}{llll}
\hline Presence & Construct & Average & Stdev \\
\hline Teaching & Design \& organization & 4.67 & 0.54 \\
& Facilitation & 4.09 & 0.85 \\
\multirow{3}{*}{ Social } & Direct instruction & 4.16 & 0.88 \\
& Affective expression & 3.31 & 1.01 \\
& Open communication & 3.76 & 0.94 \\
Cognitive & Group cohesion & 3.49 & 0.76 \\
& Triggering event & 3.87 & 0.83 \\
& Exploration & 3.86 & 0.91 \\
& Integration & 4.07 & 0.72 \\
& Resolution & 4.19 & 0.87 \\
\hline
\end{tabular}

supportive documentation, all aspects that are abundantly present in this course. Good course design contributed much to student learning experiences, as observed in the high percentage (87\%) of students that completed the course. This finding confirms the importance of the first of the three factors, namely "consistency in course design, ... [that] have been consistently shown to significantly influence the success of online courses" (Swan et al., 2000, p. 513).

The lecturer managed to provide excellent teaching and cognitive presence by innovative use of functions in the LMS and providing comprehensive formative feedback via email to students, as a whole group and as individuals. Cognitive presence was to some extent provided by peers, who challenged students to express themselves more concisely, and think beyond their own boundaries (Garrison et al., 2001). The high level of cognitive presence was an unanticipated bonus of peer review, as knowledgeable peers could contribute value beyond the knowledge base of the lecturer, irrespective of the large class size.

Students appreciated the effort their peers put into comprehensive reviews, and into understanding what they proposed. These actions also contributed to a sense of belonging. The double-blindness of the reviews provided a space to express honest opinions, and as such contributed to the measure of social presence. All three presences contributed to the formation of a community, which also promotes study success (Conrad, 2005; Johnson, 2001).

\section{Conclusions}

Innovative use of ICT enabled the lecturer to provide better quality online teaching despite the large size of the class. The quality of teaching was evident in the high success rate of the students, and confirmed in the CoI scores. According to Blignaut and Trollip (2005) social presence usually dominates in online courses, while lecturers neglect the harder to achieve cognitive engagement. The lecturer in this course managed to provide excellent teaching and cognitive presence through innovative use of functions in the LMS and other ICT's and by providing scaffolding through extensive feedback. The high score for course design contributed much to positive student learning experiences. The honest interaction during the peer review process created sufficient social presence to label the course as successful. Our findings are in line with those of Conrad (2005), who found that social presence develops as the result of cognitive and teaching interaction, and it is not a precursor to cognitive interaction, as implicated by Salmon (2003).

The perception of an "ideal size" online class lives in an unrealistic world. Education is becoming massified, and blended delivery modes are progressively containing more e-learning elements. Scarce teaching staff are stretching the boundaries to accommodate upscaled online classes. The quality of learning in supersized classes need not necessarily be inferior. When students engage in online activities and take responsibility for the quality of interaction, they can have a superior learning experience. The key to successful up scaling lies in creating opportunities for the sharing of knowledge and insight under controlled circumstances. Double-blind peer review is such an instrument that can broaden students' cognitive horizons while providing formative feedback on each other's performance. Peers can contribute to cognitive presence and a measure of social presence through a sense of belonging in a class. The $\mathrm{CoI}$ can provide the framework for designing an effective online learning environment (Arbaugh et al., 2008).

\subsection{Recommendations for further study}

Future administration of this instrument in online classes of different sizes will shed more light on the limitations of effective teaching in large online classes. Such findings will eventually inform the migration of paper-based distance education to electronically delivered mass education.

\section{References}

Anderson, T. (2004). Toward a Theory of Online Learning: Athabasca University Arbaugh, J.B., \& Benbunan-Finch, R. (2005). Contextual factors that influence ALN effectiveness. In S.R. Hiltz \& R. Goldman (Eds.), Learning Together Online. Research on Asynchronous Learning networks (pp. 123-144). Mahwah: Lawrence Erlbaum Associates, Inc.

Arbaugh, J. B., \& Benbunan-Finch, R. (2005). Contextual factors that influence ALN effectiveness. In S. R. Hiltz, \& R. Goldman (Eds.), Learning Together Online. Research on Asynchronous Learning networks (pp. 123-144). Mahwah: Lawrence Erlbaum Associates, Inc.

Arbaugh, J. B., Cleveland-Innes, M., R, D. S., Garrison, D. R., Ice, P., Richardson, J. C., et al (2008). Developing a Community of Inquiry instrument: Testing a measure of the Community of Inquiry framework using a multi-institutional sample. Internet and Higher Education, 11, 133-136.

Baker, J. D. (2004). An investigation of relationships among instructor immediacy and affective and cognitive learning in the online classroom. Internet and Higher Education, 7, 1-13.

Bhagyavati, Kurkovsky, S., \& Whitehead, C. C. (2005). Using asynchronous discussions to enhance student participation in CS courses. ACM SIGCSE Bulletin, 37(1), $111-115$.

Blignaut, A. S., \& Trollip, S. R. (2003). Developing a taxonomy of faculty participation in asynchronous learning environments -an exploratory investigation. Computers $\mathcal{E}$ Education, 41, 149-172.

Blignaut, A. S., \& Trollip, S. R. (2005). Between a rock and a hard place: Faculty participation in online classrooms. Education Change, 9(2), 5-23.

Boud, D., Cohen, R., \& Sampson, J. (1999). Peer learning and assessment. Assessment $\mathcal{E}$ Evaluation in Higher Education, 24(4), 413-426.

Boud, D., \& Tyree, A. (1995). Involving self and peers in the assessment of class participation. In D. Boud (Ed.), Enhancing Learning Through Self Assessment (pp. 93-101). London: Kogan Page.

Collison, G., Elbaum, B., Haavind, S., \& Tinker, R. (2000). Facilitating online learning: Effective strategies for moderators. Madison, WI: Atwood Publishing.

Conrad, D. (2005). Building and maintaining community in cohort-based online learning. Journal of Distance Education, 20(1), 1-20.

Feldstein, M., \& Masson, P. (2006). Unbolting the chairs: Making learning management systems more flexible. eLearn Magazine, 13.

Garrison, D. R., Anderson, T., \& Archer, W. (2000). Critical inquiry in a text-based environment: Computer conferencing in higher education. Internet and Higher Education, 2(2-3), 87-105.

Garrison, D. R., Anderson, T., \& Archer, W. (2001). Critical thinking, cognitive presence, and computer conferencing in distance education. American Journal of Distance Education, 15(1), 7-23.

Gehringer, E.F. (2001). Electronic Peer Review and Peer Grading in Computer-Science Courses. Paper presented at the SIGCSE Charlotte.

Heppner, F. H. (2007). Teaching the large college class: A guidebook for instructors with multitudes. San Francisco: Jossey-Bass.

Hewitt, J., \& Brett, C. (2007). The relationship between class size and online activity patterns in asynchronous computer conferencing environments. Computers $\mathcal{E}$ Education, 49(4), 1258-1271.

Holmberg, B. (1989). Key issues in distance education: An academic viewpoint. European Journal of Education, 24(1), 11-23.

Hughes, G. (2007). Using blended learning to increase learner support and improve retention. Teaching in Higher Education, 12(3), 349-363.

Johnson, C. S. (2001). A survey of current research on online communities of practice. Internet and Higher Education, 4, 45-60.

Juwah, C. (2003). Using peer assessment to develop skills and capabilities. USDLA Journal, 17(1).

Messineo, M., Gaither, G., Bott, J., \& Ritchley, K. (2007). Inexperienced versus experienced students' expectations for active learning in large classes. College Teaching, 55(3), 126-133.

Orellana, A. (2006). Class size and interaction in online courses. Quarterly Review of Distance Education, 7(3), 229-248. 
Rovai, A. P., \& Wighting, M. J. (2005). Feelings of alienation and community among higher education students in a virtual classroom. Internet and Higher Education, 8, 97-110.

Salmon, G. (2003). E-moderating: The key to teaching and learning online, 2 ed. London: RoutledgeFalmer

Santovec, M. L. (2004). Virtual learning communities lead to 80 percent retention at WGU. Distance Education Report, 8(8), 4.

Shea, P. J., Pickett, A. M., \& Pelz, W. E. (2003). A follow-up investigation of "teaching presence" in the SunyLearningNetwork. Journal of Asynchronous Learning Networks, $7(2), 61-80$.

Stephen, D. E., O'Connell, P., \& Hall, M. (2008). Going the Extra Mile', 'Fire-fighting', o Laissez-faire? Re-evaluating personal tutoring relationships within mass higher education. Teaching in Higher Education, 13(4), 449-460.

Swan, K. (2001). Virtual interaction: Design factors affecting student satisfaction and perceived learning in asynchronous online courses. Distance Education, 22(2), 306-331.
Swan, K., Shea, P.J., Fredericksen, E.E., Pickett, A.M., \& Pelz, W.E. (2000). Course Design Factors Influencing the Success of Online Learning. Paper presented at the WebNet 2000 World Conference on the WWW and Internet, San Antonio.

Swan, K. P., Richardson, J. C., Ice, P., Garrison, D. R., Cleveland-Innes, M., \& Arbaugh, J. B. (2008). Validating a measurement tool of presence in online communities of inquiry. e-mentor, 2(24), 1-12.

Tomei, L. A. (2006). The impact of online teaching on faculty load: Computing the ideal class size for online courses. Journal of Technology and Teacher Education, 14(3), 531-541.

Topping, K. (1998). Peer assessment between students in colleges and universities. Review of Educational Research, 68(3), 249-276.

Woodill, G. (2004). Where is the learning in e-learning?: A critical analysis of the elearning industry. Retrieved Aug 12, 2006, from http://www.elearningguru.com/ wpapers/e-Learning_analysis.pdf 